Losing Sight of Land: Tales of Dyslexia and Dyspraxia in Psychophysical Actor Training. (ID: 1415955 DOI:10.1080/19443927.2017.1415955)

Journal: Theatre, Dance and Performance Training

Estimated Publication date - 24 Jan 2018 (Online)

Authors: Daron Oram 


\title{
Losing Sight of Land: Tales of Dyslexia and Dyspraxia in Psychophysical Actor Training.
}

\section{Daron Oram}

\begin{abstract}
This article reports on the findings of a research project into the impact of psychophysical actor training methods on neurodiverse students. It illustrates how the application of a Social Theory of Learning Difference reveals the mechanisms whereby these training methods dysconsciously discriminate against those students who are dyslexic and/or dyspraxic learners. The research findings recognise the inherent value of psychophysical methods in the training of actors but suggests that there is a need to move away from a singular Psycho-Medical Theory of Learning Difference and to adopt a framework of learning difference based on the Social Model of (dis)ability, which requires institutions to adapt their provision to better meet a diverse range of needs. A revision of psychophysical approaches is proposed, which draws on a neuroscientific theory of experiential practice and a psychological framework of actor engagement. This new approach seeks to enhance the effective communication of embodied knowledge and skills in diverse actor training contexts and to allow students who are dyslexic and/or dyspraxic learners equal access to that learning.

\section{Keywords}

Psychophysical, Dyslexia, Dyspraxia, Neurodiversity, Actor Training.

\section{Context}

This research is set within a shifting socio-political context that directly affects students with Specific Learning Differences (SpLDs). The UK government has made cuts to the Disabled Students Allowance (see Johnson 2015) and there is a directive to move towards a more inclusive approach (Dept. of Education 2017). At the same time, conservatoires are working positively to increase access to actor training as part of an 
industry wide move to enhance diversity and representation within the performing arts.

This welcome development is helping to increase the number of acting students who come from low socioeconomic backgrounds; however, many of these students have had less access to support for their learning prior to entering training (see American Psychological Association) and this puts increasing pressure on an already contracted structure for learning support within HE. This context further enhances the need for actor training to be better aligned to the needs of students with SpLDs.

This case study adopts a heuristic perspective within an overarching grounded theory (Glaser \& Strauss 1999) methodological approach. The ultimate product of any heuristic enquiry 'is, in some form or another, a story of personal transformation that has the potential to transform others' (McLeod 2011, p. 207). The narrative nature of this heuristic enquiry, combined with the embodied experiences inherent in Voice Studies (see Oram, 2015), requires the reader to immerse in the world of the researcher and their subjects. For this reason, it is necessary that this article draws significantly on the firstperson experiences and journal notes of the author and the verbatim responses of participants. Like all good stories, this one begins with an inciting moment, a moment of crisis...

\section{Set adrift, the story begins...}

This narrative is based on real events; names have been changed and certain details are highlighted and abridged to speak to the reader. Notes from my reflective journal are given in italics. 
'I spent most of the class leading the students through some exploratory exercises on the floor. We were working with basic concepts of breath, relaxation and vibration using a range of visualisation and physical positions to engage with physical release, an engagement with a deeper connection of breath into the pelvis, and a sense of releasing vibrations from this deep instinctual area of the body. We stopped to reflect on the process a couple of times along the way and all seemed to be going well. Students reported that they felt more open, that they were finding more breath in a deeper way and that their vibrations were more noticeable in their bodies. At the end of the final exploration of the morning, after a number of students had reported further fresh, new and interesting experiences, and with five minutes to go, Sheryl announces that she has "felt nothing" and that she "wasn't getting it." I wanted to help her move away from this negative thought and attempted to talk her back to a moment when she was feeling that she was "getting it". I was hoping that this could be a moment for her to return to in the next class but as she reluctantly tried to remember back she broke down in tears.'

This was not the first time that Sheryl had responded to the work in this way. On previous occasions, Carlo, emboldened by Sheryl's feedback, had also spoken up to say that he, too, had not understood the work. Meanwhile, another student, Casey, shrank away from attention, fed back little and showed all the outward signs of self-conscious disengagement from the work. I knew that all three of these students were dyslexic and/or 
dyspraxic learners. I have a good relationship with the dyslexia co-coordinator, Tanya Zybutz, and I decided to go and talk to her to see if she could shed any light on the situation.

'Tanya wonders whether the problem is with the Linklater voice work that I'm teaching. She asked whether it was appropriate for students with learning differences as they don't seem to be getting it. I've taught this work for eight years and it's seemingly been going really well, so, I don't understand why it should be such a problem now? On top of all of this, I've just picked up an MA Voice Studies dissertation to mark and the research is looking at looking at Dyslexia and Voice Work with a particular focus on perceived challenges within the Linklater approach.'

This point of crisis came as a shock. Previously, my students had been achieving well and the positive impact of my work had been recognised through various quality assurance mechanisms and exercises. I had used the psychophysical Linklater approach for some time. I had specifically focussed on this approach and trained as a designated teacher with Kristin Linklater because I found it one of the most effective approaches to use with acting students. Yet, here I was, hearing from multiple sources that the work was not working for these students.

Feeling lost, looking for landmarks: context and methodology

I began to examine this situation to try to understand why this it had suddenly occurred. I had begun work at Central a couple of years prior to this moment of crisis. I train 
actors on the BA Acting Collaborative and Devised Theatre Course (BA Acting CDT), described on the Central Website as follows: -

'This innovative and rigorous actor training emphasises the creation of new theatre and embraces a multi-cultural and multi-disciplinary methodology. Students graduate with the skills to work in classical and contemporary theatre, film, radio and screen, as well as being accomplished makers of their own work.' (RCSSD 2017)

This combination of contemporary devised theatre approaches with actor training methods within a conservatoire setting make BA Acting CDT a unique context within which to work. This innovative course 'includes the psychophysical techniques of Jacques Lecoq, Michael Chekhov, Constantin Stanislavski, Feldenkrais and Kristin Linklater, and emphasises an embodied and experiential approach.' (ibid). The process of psychophysical training develops students embodied knowledge and skills and the Linklater voice work is of great value for both the psychological realism and more contemporary theatre making practices on the CDT course. One student captured this experience in the comment, 'I realise that you're not giving me a voice but are helping me to find the voice l've always had.'

The following list is a set of positive attributes commonly assigned to people who are dyslexic learners.

- Good powers of visualisation

- Artistic talents 
- Good practical and problem solving skills

- Creative thinking skills, including lateral thinking

- A holistic (big picture) approach to problem solving

- An intuitive empathy with others. (McLoughlin et al. 2002, p. 8)

Taken out of context, this list could easily be a description of the ideal candidate for the CDT Acting course. This goes some way to explaining how, after auditioning around five thousand students each year, the course can have a cohort of students that sometimes has $70 \%$ with some sort of learning difference. Many acting courses have a higher than average number of students with dyslexia - (see Leveroy 2013b and Whitfield 2016b); however, the Acting CDT course regularly has a level of learning needs beyond that common to other courses. This high level of neurodiversity in a cohort of students that have a strong sense of self and ability to identify their own needs has helped to draw my attention to the problem outlined above. I now believe that this problem may well have always been there to some extent but, for several reasons, including a lower percentage of neurodiverse students in my previous work, I had simply not been aware of it.

Whilst I was beginning to understand how this situation had suddenly occurred, I had no idea as to how to resolve the problem and it was at this point that I set out to address this as a research project. The heuristic nature of the research was clear from the outset I was entering into 'a process of personal immersion in a topic or question, leading to new insights' (McLeod 2011, p. 206) and, given the inciting moment of personal crisis that I had experienced, I certainly felt 'a willingness to surrender to the research question', (ibid p. 207, original italics). 
There has been very little research into actor training and Specific Learning Differences (SpLDs) and what there has been has focussed mainly on text work and the dyslexic learner see (Leveroy 2012, 2013a, 2013b, 2015 and Whitfield 2009, 2016a, 2016b). Colin Farquharson and Tanya Zybutz's 2016 article, considers the experience of the dyspraxic actor and psychophysical training. However, other than this article, there has been no discussion of dyspraxia and acting. With few appropriate resources to draw upon, I needed to focus on the specific needs that were arising within the Acting CDT course as a case study to 'investigate in depth... within its real-life context' (Yin 2009, p. 18).

I expanded my investigation beyond my own voice classes in the hope that I could draw on themes across the core training disciplines of voice, movement and acting, and identify models of work that were already being successful. Due to the lack of published work on acting and SpLDs, I did not have enough information to form a hypothesis and test this through an action research process. I was also wary of drawing on existing research into education, dyslexia and dyspraxia, as this mainly focusses on primary and secondary education in STEM ${ }^{i}$ subjects. There was a need to develop theory specific to the practice and context itself. Grounded Theory (Glaser and Strauss 1999) offered a valuable solution to this methodological question.

Grounded theory is a qualitative methodology from the social sciences. The emergent nature of Grounded Theory makes it applicable to the needs of this study. As a methodology, it seeks to generate theory, which emerges from data gathered within the research process. 'Grounded Theory does not force data to fit with a predetermined theory' 
(Cohen et al. 2011, p. 599) and does not begin with a literature review; rather, it uses research methods to investigate the area of research first.

'An effective strategy is, at first, literally to ignore the literature of theory and fact on the area under study, to assure that the emergence of categories will not be contaminated by concepts more suited to different areas.' (Glaser and Strauss 1999, p. 37)

This approach allowed me to ground myself in the territory at the site of the problem. Using reflective practice, thick journaling, focus groups, peer observation and a critical friend I could explore this territory from multiple perspectives and chart the processes of training within a diverse context to develop my own theoretical concepts. I was then able to compare these emerging theories with existing literature to re-examine them from other perspectives until they reached a point of 'saturation' (ibid, p. 61). The rest of this article maps out these emergent theories, which I have since begun to test through action research processes and refine through conversations with actor training practitioners both nationally and internationally.

Spreading the map and changing the key: a psychophysical problem and a social theory.

In the initial stages of the research process, I ran a focus group and I began to see that students were experiencing similar problems, to varying degrees, across all the psychophysical aspects of the core training. 
'My hardest was biomechanics, it brought up all this stuff for me...across the training you have to be quite self-led, self-aware, which is quite difficult... I found Chekhov technique quite hard. I'd get the same points and not know how to change them...in Feldenkrais, I didn't know what I was looking to do or feel, I didn't grasp why we were doing it.' (focus group notes).

It was a relief to discover that my personal approach was not the sole cause of problems for my students. Nor was the problem, as had been initially proposed, confined to the Linklater method. It was becoming apparent that the approaches used within a range of psychophysical training were having a negative impact on students with SpLDs.

This insight shifted the focus away from a problem that the students with SpLDs have and onto a problem of the training itself. This paradigm shift in the research was further enhanced by shift in theoretical perspective. The predominant theoretical model of learning difference within tertiary education is the psycho-medical model of learning difference, which 'seeks to objectify dyslexia [and dyspraxia] as a condition' (Macdonald 2010). The paradigm shift described above led me to adopt an alternative theoretical perspective, that of the social model of learning difference. Here, a simplified example can help explain the difference.

Imagine a school for the art of paper cutting. Every year the school knows that a certain number of left-handed students will join the course; however, the art of paper cutting is traditionally taught using right-handed scissors and this school continues to do so. 
Using a psycho-medical model, the school would approach this problem by diagnosing the left-handed students and giving them additional one-to-one support to help them adapt to the right-handed scissor approach. Conversely, the social model would lead the school to teach with both left-handed and right-handed scissors so that all students would have an equal access to the learning.

Rather than seeing the source of the problem as a deficiency in students' ability to learn, I began to understand that there were barriers to learning that some of the constructs and values of psychophysical training create, as Leveroy $(2013$, a) explains, 'it is these socially constructed values, which make dyslexia a "problem" and it is society's institutions which need to adapt'.

'I realise now that there are some deeply learnt practices that I hold onto, which feel key to the success of my work and yet may be causing problems for my students with SpLDs. I need to be open to letting go of some of the approaches that are central to how I have been trained. At the same time, I have no idea what a new approach to training might look like. I feel like I'm losing sight of land with no sense of direction...' (Journal notes)

This was my heuristic moment of 'surrender to the research question, to a sufficient extent that a personal transformation' (McLeod 2011, p. 207) could take place. The challenge that I faced is echoed by Whitfield 'I had little conception about how I might adjust my practice based on an accommodation of learning differences or that other ways of working might have cogency' (2016, p. 115). I had, in many ways, to begin again. The core 
embodied psychophysical knowledge and skills that I wanted to share with my students did not change; however, I needed to spend time collaborating with my students to find new ways to engage with them through the training.

The social model helped to focus my attention onto the phenomena occurring within the training itself rather than an aetiology of SpLDs. The paper cutting school example, again, helps to explain this focus. To come to a decision about which scissors to use, the school could have spent a great deal of time and energy trying to understand why some people are left-handed, using neuroscientific, psychological and genealogical research. However, from the perspective of the social model, all they need to understand is how the chosen teaching methods affects a particular group of students within a specific learning environment.

By adopting the social theory, I did not need to make sense of unclear definitions of dyslexia and dyspraxia as deficiencies ${ }^{i i}$. Instead, my research aimed to build up a more detailed picture of how psychophysical training methods affected students with learning differences to then change the methods to better suit the neurodiversity of the student cohort.

\section{Charting the territory.}

In Deborah Leveroy's (2013b) article on acting and dyslexia she notes that 'the impact of social aspects on the individual's lived experience is key to understanding the participant's reality.' Through my own research, I have been able to map out the impact of 
psychophysical training on the lived experience of my dyslexic and/or dyspraxic studentsiii. Dyspraxic and 'dyslexic people are not a homogeneous group where one method will suit all' (Whitfield 2016a, p. 115). There are contradictions in students' experiences and this requires an approach that acknowledges and engages effectively with diversity. However, many experiences occur regularly enough to indicate a pattern across a range of neurodiverse participants and these patterns have helped me to build up a clearer picture of the areas where psychophysical approaches can cause problems for the dyslexic and/or dyspraxic learner.

The experiences of Sheryl in the opening narrative show how a long physical exploration of new work, which took her through a shifting physical orientation and incorporated specific visual imagery to introduce the work, led her to a place where she reported that she had "felt nothing" and "wasn't getting it." Over the course of my research, I recognised this pattern more and more. I also noted students who, when asked to work eyes closed, would not hear the instructions and keep being left behind. Some dyslexic and/or dyspraxic students would make progress when given personal attention in class and, yet, in the next class, were not able to retain any postural or vocal adjustments that had been made. For example, Lizzie, who I had taken slowly through a series of tongue exercises in an individual tutorial seemed to have no recall or access to the same embodied work in a subsequent group session. Casey, echoed this experience when she said 'in $a$ tutorial, you get it, but then it's gone' (focus group notes).

In these and other students, I observed that they could get confused about left and right and they would often struggle to learn a short text or sound sequence quickly by ear. 
Students often demonstrated an inability to retain rehearsal work from one day to the next or to be able to apply verbal performance notes. There is a common issue with a lack of selfesteem and this seems related to students' ability to feedback in class. Sheryl and her classmates, Carlo and Casey, all reported an inability to do the work by themselves 'I've not got strategies to sustain the work...the teacher actually helps but I can't have the teacher by my side every day' (ibid). Other themes that emerged through feedback, observation, and discussion with other tutors included students who would get more confused when several alternative explanations were given; they might get lost if the work used imagery that changed rapidly or lose their way when their physical orientation changes e.g. from floor to standing. Linklater voice uses the piano in call and response work and, in discussion with singing colleagues; we noticed a tendency to struggle to match pitch in our dyspraxic students. Picking up choreography has obvious challenges for dyspraxic students but it also emerged that students seem to lack a sense of the back of their body or 3D orientation and may block others on stage without noticing, or, find it hard to re-orientate their performance in space. Whilst people who are dyslexic learners have 'good powers of visualisation' (McLoughlin 2002, p. 8), it emerged from the research that many students seem to struggle to apply very specific imagery, as Helen says, 'if it's someone else's image then I get anxious and think "I'Il never get that"' (focus group notes).

Alongside these perceived difficulties, the creative advantages of neurodiversity, discussed earlier, emerge as a much stronger theme within the theoretical framework of the social model. Further to the positive dyslexic attributes quoted earlier from The Adult Dyslexic (2002), I found that neurodiverse students often demonstrate a creative and innovative perspective within the psychophysical work, sometimes sharing images or 
observations that are unusual or unexpected. For many, their preference is to come up with their own images, rather than ones prescribed by the tutor. 'Sometimes I try and imagine what [the teacher] is imagining and I don't really like it but if I imagine my own stuff and get a bit wacky with it, it helps' (focus group notes). They also tend to see the bigger picture or arc of a progression of work, rather than focussing on the specific details. 'It's hard to come into class and think about the relaxation of my tongue when there's more important shit in my brain like, "what am I going to do as a creative artist?"' (ibid). The social model allows for a recognition of these strengths and helps to avoid an assumption that dyslexic and/or dyspraxic students have come to acting because they are unable to do anything else.

Additional to observing the impact of the work on the students, it is also valuable to note what can happen to the person leading the work. Within my early journaling for this case study, I noted moments of 'frustration with students who were just not getting it.' Sometimes, I felt that a student 'was not working hard enough' or that perhaps they were simply 'lazy'. Even though I would not make these feelings explicit, it seems that students still pick up on them. One student commented 'you think the teachers are going to think you're disengaged or don't care. We do care, we think about it all the time!' (Focus group notes). It is important to recognise this level of care and hard work put in by students with SpLDs, whilst they may be falling behind, they are working incredibly hard to keep up with their neurotypical classmates. I now monitor myself for feelings of frustration and use them as a prompt to spend more time observing a student at work. Often, it is these feelings and/or a recognition of some of the observable phenomena outlined above that have led to the eventual screening and diagnosis of students who were previously undiagnosed with dyslexia and/or dyspraxiaiv. 


\section{Sensing a direction: neuroscientific model.}

As I sought to understand the issues more deeply, I began to draw on the limited published research on acting and SpLDs. In their discussion of Psychophysical Performance and The Dyspraxic Actor, Zybutz and Farquharson (2016) discuss the challenge that dyspraxic actors have in translating the intellectual understanding of their character and how they express...this with their physical bodies'. (p. 83) In exploring this issue, they draw on Dr Norman Farb et al's (2007) research into mindfulness and neuroscience. Zybutz and Farquharson draw on these research findings to focus specifically on the issue of cognitive and sensory translation for the dyspraxic actor. When I looked at my own research findings from the perspective Farb at al's model, I found a key to understanding how psychophysical training methods themselves were dysconsciously discriminating against neurodiverse students.

Psychophysical training seeks to heighten an actor's awareness of the inseparable unity of the mind and body. This approach recognises that 'in every physical action, unless it is purely mechanical, there is concealed some inner action, some feelings.' (Stanislavski 1961, p. 228) In my own approach to training, I aim to train, what Linklater calls, the actor's "quartet" of body, voice, emotion, and intellect, each playing their part in balance and harmony and with none super- or sub-ordinate to others.' (Pensalfini 2011, p. 60).

Farb et al's research provides an effectively simple model, which gives an insight into what happens in the brain during this type of psychophysical work. The research identifies 
two neurological modes of self-awareness, 'narrative focus' (NF) and 'experiential focus' (EF) (2007, p. 314). 'EF was characterised as engaging present-centred self-reference, sensing what is occurring in one's thoughts, feelings and body state' whereas 'NF was characterised as judging what is occurring...and allowing oneself to be caught up in a given train of thought'(ibid). Essentially, there are two areas of the brain at play: one that deals with the ability to stay in the present moment experience and have an awareness of feelings and sensations in the body and another that thinks about the experience and processes thoughts about the past or the future. The most striking finding in Farb at al's research is that these two functions are 'inversely related' (Chaskalson 2014, p. 136).

When this model is applied to acting, it becomes clear that to work in a moment-bymoment state of awareness, an actor will need to be able to switch their attention away from a 'default' (Farb et al 2007, p. 314) narrative focus to get in touch with their bodily sensations and emotions. The process of adopting a present state awareness of self is a familiar concept within psychophysical actor training. Michael Chekhov constantly urged actors to move away from using their thinking mind, from analysis and rational thought, and instead to experience their psychology through their body.' (Daboo 2007, p. 267).

Discovering that the narrative mode and experiential mode are inversely related has helped to clarify the issues for neurodiverse students. Using this theory as a critical lens, I have begun to see how the problems that neurodiverse students encounter within psychophysical training cause the students to stay in, or return to, a narrative mode of thinking about the work rather than being able to immerse and remain in an experience of the work. 
I have already discussed how neurodiverse students can have difficulty following instructions with their eyes closed; how they meet difficulties when following sequential instructions, and have challenges with orientation in space or when prescribed imagery is used to introduce new work. The narrative versus experiential neuroscientific theory explains the impact of these problems. If the training approach preferences somatic eyes closed experiences or leads students through long exploratory sequences, using visual imagery and regular changes of orientation in the room, neurodiverse students are constantly challenged in their ability to stay in an experiential mode. Each time they get lost and try to work out what is going on in the class, what to do next, or simply where they should be in the room, students move out of the experiential psychophysical mode and into an analytical narrative mode. Due to the inverse relationship of these modes of selfreference, each time they return to this narrative mode, they are unable to connect to feeling and sensation in their bodies. This is borne out in focus group comments: -

'Often it's a long routine and at the end you'll feed back but...you really don't know what you were meant to do or feel or say or think...consciously [narrative], you know why you are doing it but there is something missing [experience].' (Focus group notes)

Reflecting on Sheryl's experiences, which I described in the opening section of this article, it is now far easier to understand what was going on for her. Sheryl's feedback that she had "felt nothing" and that she "wasn't getting it" should not have come as a surprise. The various challenges that the class had thrown up meant that she was unable to immerse in the work as her brain was fully occupied with the narrative function of holding on to what 
was coming next. Throughout the class she had been working exceptionally hard to know where she was in relation to what had just happened or was about to happen and, at the same time, she trying to incorporate narrative verbal images into her physical experience. Sheryl's hard-working focus on keeping up with the class inevitably counteracted her ability to connect to her somatic experiences.

Understanding how aspects of psychophysical training impact negatively on the ability of neurodiverse students to enter and maintain an experiential mode has been invaluable in the process of beginning to revise the work but it is only one half of the theoretical framework that has emerged from my research.

\section{Going around in circles: a psychological framework.}

The second half of the emergent framework involves an understanding of how the training approaches also affect the psychological functioning of students with SpLDs.

In the class discussed above, Sheryl's classmates 'reported that they felt more open, that they were finding more breath in a deeper way and that their vibrations were more noticeable in their bodies.' In this context, Sheryl fed back that she 'didn't feel anything' and 'wasn't getting it'. It is easy to understand how a student in this situation can experience a sense of failure that, in turn, affects their psychological well-being.

It is common for neurodiverse students to self-critique more readily than other students. As Mcloughlin et al point out, 'They do not value their abilities or their 
achievements...having become used to getting things wrong' (McLoughlin at al. 2002, p. 5). McLoughlin et al list the following secondary characteristics of dyslexic learners, saying that they are every bit as stigmatising and debilitating as the primary features.

- Low self-confidence.

- Low self-esteem.

- Anger and frustration.

- Anxiety.

- Problems with social interaction. (ibid)

Within my own observations, I identified that students with SpLD's would more readily self-critique and lose confidence. This does not; however, match with the confidence and positivity demonstrated by these students at audition. For many students with SpLDs, acting has been the activity where they have found a sense of self-confidence and excelled. However, acting taught at secondary level, or experienced through youth/amateur theatre, generally does not include the sophisticated psychophysical approaches used within professional training. It can be distressing for students who have pursued their creative strengths and achieved a coveted place at drama school suddenly to encounter difficulties when they engage with the approaches used in the training. Eide and Eide point out that the crucial years from 'kindergarten to mid-adolescence, are when the battle to develop confidence, resiliency, and a positive self-image is largely won or lost' (2011, p. 205). Many students who are dyslexic and/or dyspraxic learners have experienced failure at this crucial point in their lives, either in STEM subjects and/or on the sports field. When they begin to 
encounter problems within their actor training it is all too easy for them to enter a familiar cycle of failure.

The cycle starts when a student compares their experiences to that of their classmates. They notice that others in the group are reporting positive experiences, whilst they themselves were simply struggling to keep up and did not feel anything. This leads to a feeling of failure, affirmed by negative educational experiences in the past, and the student quickly becomes self-critical and loses confidence - as these comments from students show.

'I knew it was going to be hard...things like movement and biomechanics sent me back to when I was five or six and felt I was always the odd one out... I thought I would feel that other people would get my brain but they still don't...I found it really hard and really frustrating and I didn't feel I could talk to people...I felt really lost and helpless and before I'd go into a class I'd feel really stressed as I'd not got the class from day one.' (Focus Group Notes)

This process is only the beginning of an ongoing cycle of failure. The cycle continues and is compounded by one of the central tenets of nearly all psychophysical approaches. Within psychophysical training, explorations of new work are often led with an open-ended approach. The work is rarely demonstrated beforehand and the aim of the work, as in what the students might feel or discover, is rarely explained. This approach aims to stop students mechanically mimicking or end-gaining - a concept clearly outlined by F.M. Alexanderv:- 
'It is essential, in the necessary re-education of the subject through conscious guidance and control, that in every case the "means whereby" rather than the "end" should be held in mind. As long as the "end" is held in mind instead of the "means," the muscular act, or series of acts, will always be performed in accordance with the mode established by old habits.' (1996, p. 117-8)

There is a well-founded desire that drives this deeply embedded philosophy within so many psychophysical approaches. The hope is that students will make their own discoveries and, in so doing, own their burgeoning embodied knowledge for themselves. The affirmation that there is 'no right or wrong' and the instruction that the students should simply 'immerse in the work and see what happens' often accompany this approach.

'You must sacrifice your desire for results to the experience of causes. Although you will need your intellect to understand the exercises, you must abandon it when doing them in favour of feelings and sensory impressions. You must not jump to conclusions as to what is right or wrong because you are already a well-developed censor of self. Nor can you trust your judgement, since it is biased by habitual ideas of good and bad and wary of new experiences.' (Linklater 2006, p. 11) 
Here, Linklater encourages an experiential rather than narrative mode of selfreference, which, as has been shown, is a valuable component of all psychophysical work. However, there is a common assumption across training methods that all students are equally able to abandon their critical faculties. For students with SpLDs, this approach is more likely to take them to a place where, rather than immersing in the open-ended experience, they simply assume are getting it wrong. Even if the technical hurdles of following the class are overcome, the very nature of an open-ended exploration can take these students out of the experience and into a self-critical narrative mode, as these focus group responses indicate: -

'I found it hard as I didn't really know how I was doing... "nothing is right or wrong", we all know that there's a right or wrong...for me it makes me feel, "oh it's going to be wrong", so, it is wrong... "see what happens" puts me into a place that's not useful... what it feels like to me is "just see how much you are fucking it up and then be ok with how much you fucked it up!"'

This finding led to a further heuristic moment of transformation within my research. So many of the processes that I have undergone as an actor in training, and as a teacher in training and practice, have been founded on experiential learning principles. Based on the theories of John Dewey and John Piaget, experiential learning approaches come out of the same liberal humanist traditions as many of the psychophysical training methods I have been investigating. The key point to note here is that these training approaches were never designed to sit within a contemporary higher education structure. On open-ended 
experiential investigation of self and a slow progressive development of skills is not necessarily a problem. The problems arise and are compounded when this approach is placed within the temporal confines of formal education structures. In these structures, students are assessed on their progress on a pass/fail or graded basis. The outcome of these assessments determines students' future academic progression and has implied value in terms of their future professional potential. The combination of experiential development with these assessment structures can be challenging for the most able student. However, when a neurodiverse student falls into a cycle of failure and there is an impending assessment at the end of term, the affirmation in class that there is 'no right or wrong' is seemingly unethical. The solution to this conundrum is not to reject experiential learning; the very nature of embodied knowledge and skill development requires students to learn through an experiential rather than narrative mode. The challenge is to find a way of enabling students with SpLDs to engage with experience in a meaningful, structured and supported way that does not discriminate against them cognitively or psychologically.

If these problems are not addressed, an all too familiar pattern can emerge. The student struggles to follow the work and gets 'stuck in their head' and feels little in the way of physical sensation. Because they have not felt what others have, they become self-critical and can sense even less in their bodies. Not knowing what is expected from the work, they assume that they are wrong and the process of self-critique enhances. This cycle repeats until their ability to connect to their bodily experiences all but disappears. ${ }^{\text {vi }}$ When this process continues over time, I have observed students progressively disengage from the work and find ways of hiding from attention or discussing their experiences. Alternatively, students will choose a dissembling tactic, copying the types of phrases that other students 
use in feedback to give the impression that they have understood the work. It is common for students who have used this dissembling tactic successfully to reach a point where there is then an unexpected and catastrophic failure later in their training.

\section{Looking back and travelling on.}

As can be seen from the evidence above, students rarely share their experiences of not knowing what is going on, and I am indebted to those who have taken that step and led me to this path of research. The grounded theory methodology used in this research has enabled me to develop a theoretical framework for understanding how psychophysical approaches to training actors can disconsciously discriminate against students who are dyslexic and/or dyspraxic learners. The heuristic nature of this research, coupled with the adoption of a social theory of learning difference, has allowed me to undergo a transformation, which has affected my theoretical perspectives and my practical approaches. I have seen that there is a need to change the approaches used within psychophysical training to communicate valuable embodied knowledge and skills effectively to all students on an equal footing. By broadening this research to encompass the experiences of psychophysical approaches in movement and acting, as well as voice, and by drawing on neuroscientific theory and a psychological framework that can be applied to the acting process, the findings of this research will provide insights for practitioners in training contexts beyond the immediate boundaries of this case study.

The second phase of this research involves an adaptation of approaches to psychophysical training based on the emergent theories identified here. The core embodied 
knowledge and skills of the psychophysical work have not themselves changed. I am developing a set of guiding principles that help students to remain within an experiential mode as much as possible. The Sheryl of the future understands her own meta-cognitive processes so that she can locate herself within her learning. She always has the option to work eyes open and receives lots of hands-on physical anchoring, guided orientation in space, and support to learn how to translate verbal or visual images into physical experiences. She always knows where she is in her learning as she receives each knew principle one at time, with a clear demonstration of what is expected, and the opportunity to explore this in peer-led learning processes that shift the overall power dynamics within the training.

Interestingly, a shifting of power dynamics in the studio has been central to the open-ended nature of this practice-based research. I have been required to occupy the place of 'not knowing' rather than my students and this shift towards a more radical pedagogy, akin to the work of Friere (1996) and Rancière (1991), has already had a positive effect on student experiences. 'It really feels like we're teaching him as much as he is teaching us...It doesn't feel like he's been teaching for ten years and we're just another instalment of people coming through...I always leave feeling l've learnt something.' (Focus Group notes).

\footnotetext{
i Science, Technology, English and Maths.

ii In his 2010 paper Towards a social reality of dyslexia, Stephen MacDonald recognises that 'in the UK, definitions of dyslexia have been reported to be unclear'. In terms of dyspraxia,
} 
Afroza Talukdar (2012:8) writes that 'nationally and internationally, there continues to be a lack of consensus regarding both the definition and description'.

iii My research has included students who are dyslexic, dyspraxic or both. There has been much discussion as to the overlap and neurological causes of these conditions (see Kirby, A and Drew, S (2003:1-6) and Reid, G (2009: 10-11); however, taking a social model within a grounded theory framework I focus on the phenomena occurring within my study without needing to attribute this to specific learning conditions. Anecdotally, some aspects of my changing practice also seem beneficial for students with ADD/ADHD.

iv Whilst diagnosis fits with the psycho-medical model that I have moved away from in my own work, it does open up valuable additional learning support and I recognise that for many of my students this has been of immense value to them.

${ }^{\vee}$ F.M Alexander is the originator of the Alexander Technique. The principles of this technique are taught, to some degree, on many actor-training programmes.

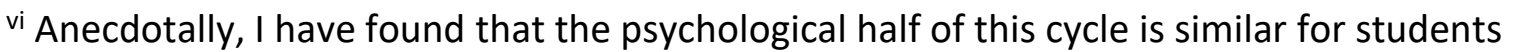
who are not dyslexic and/or dyspraxic learners but have low self-esteem stemming from other aspects of their mental health and well-being. Adaptations made to my teaching and learning approaches seem to be having a positive affect for these students as well.

\section{6 words}

\section{Bibliography}

Alexander, F. Matthias. (1996) Edited by Jean M. O. Fischer. Man's Supreme Inheritance: Conscious Guidance and Control in Relation to Human Evolution in Civilization. Mouritz, UK American Psychological Association. Education and Socioeconomic Status. American Psychological Association. Available at http://www.apa.org/pi/ses/resources/publications/education.aspx [accessed 30/11/2017] 
Chaskalson, M., 2014. Mindfulness in Eight Weeks. Harper Thorson, London.

Cohen, L., Manion, L. \& Morrison, K., 2011. Research Methods in Education. Routledge, New York

Daboo, J., 2007. Michael Chekhov and the embodied imagination: Higher self and non-self. Studies in Theatre and Performance. Volume 27, Number 3. Intellect Ltd. Doi:

10.1386/stap.27.3.261/1

Dept. of Education, 2017. Inclusive teaching and learning in higher education. Dept for Education, UK. Available at https://www.gov.uk/government/publications/inclusive-teaching-andlearning-in-higher-education [Accessed 30/11/2017]

Eide, B. and Eide, F., 2011. The Dyslexic Advantage: unlocking the hidden potential of the dyslexic brain. Hay House UK Itd, London.

Farb N.A.S., Segal Z.V., Mayberg H., Bean J., McKeon D., Fatima Z., Anderson A.K., 2007. Attending to the present: mindfulness meditation reveals distinct neural modes of selfreference. Social Cognitive and Affective Neuroscience, 2(4), 313-122. Oxford University Press doi:10.1093/scan/nsm030

Friere, P., 1996. Pedagogy of the Opressed. Penguin Books, London, England.

Johnson, J., 2015. Disabled Students' Allowances: Written statement - HCWS347, Dept. of Business Innovation and Skills, UK. Available from:

http://www.parliament.uk/business/publications/written-questions-answers-statements/writtenstatement/Commons/2015-12-02/HCWS347/ [Accessed 30/11/2017]

Glaser, B and Strauss, A., 1999. The Discovery of Grounded Theory: Strategies for Qualitative Research. Aldine de Gruyter, New York.

Kirby, A and Drew, S., 2003. Guide to Dyspraxia and Developmental Coordination Disorders. David Fulton Publishers, London.

Leveroy, D., 2012. Dyslexia and sight-reading for actors. Music, other Performing Arts and Dyslexia Ed Sally Dunt, British Dyslexia Association, Bracknell, UK.

Leveroy, D., 2013a. Enabling performance: dyslexia/, (dis)ability and 'reasonable adjustment' Theatre Dance and Performance Training 4:1 87-101 DOI 10.1080/19443927.2012.748687

Leveroy, D., 2013b. Locating dyslexic performance: text identity and creativity, Research in Drama Education: The journal of Applied Theatre and Performance, 18:4, 374-387, DOI: $10.1080 / 13569783.2013 .836919$ 
Leveroy, D., 2015. 'A date with the script': exploring the learning strategies of actors who are dyslexic. Theatre, Dance and Performance Training, 6:3 307-322, DOI:

10:1080/19443927.2015.1065464

Linklater, K., 2006. Freeing the Natural Voice: Imagery and art in the practice of voice and language. Nick Hern Books, London.

MacDonald, S., 2010, Towards a social reality of dyslexia. British Journal of Learning Disabilities 38: 271-279 10.1111/j.1468-3156.2009.00601.x Blackwell Publishing Ltd.

McLeod J., 2011. Qualitative Research in Counselling and Psychotherapy. Sage Publications Ltd, London

McLoughlin, D., Leather, C. and Stringer, P., 2002. The Adult Dyslexic. Whurr Publishers, London and Philadelphia.

Oram, D., (2015), Research and practice in Voice Studies: searching for a methodology, Voice and Speech Review. DOI:10.1080/23268263.2015.1059674

Pensalfini, R., 2011. Re-imagining the Actor's Quartet. Mosaic: a journal for the interdisciplinary study of literature, vol. 44 no. 1, 2011, pp. 65-87. Project MUSE, muse.jhu.edu/article/418759.

Rancière, J., 1991. The Ignorant Schoolmaster: Five Lessons in Intellectual Emancipation. Translated by Kristin Ross. Stanford University Press, Stanford, California.

RCSSD, 2017. Acting CDT, BA. Royal Central School of Speech and Drama, London. Available at http://www.cssd.ac.uk/course/acting-cdt-ba [Accessed 18/10/2016]

Reid, G., 2009. The Routledge Companion to Dyslexia. Routledge, Abingdon, UK.

Siegel, D., 2007. Mindfulness training and neural integration: differentiation of distinct streams of awareness and the cultivation of well-being. Social, Cognitive and Affective Neuroscience, 2: 259-263. Oxford University Press DOI:10.1093/scan/nsm034

Stanislavski, C., 1961. Creating a Role. Methuen, London.

Talukdar, A., 2012. Dyspraxia/DCD Pocketbook. Teachers Pocketbooks Hampshire UK.

Whitfield, P., 2009. Shakespeare, Pedagogy and Dyslexia. The Moving Voice: The Integration of Voice Movement Studies presented by the Voice and Speech Review. Voice and Speech Trainers Association

Whitfield, P., 2016a. Towards and emancipatory praxis of pedagogy: suppoting acting students with dyslexia when working on Shakespeare. Voice and Speech Review, DOI: $10.1080 / 23268263.2016 .118918$ 
Whitfield, P., 2016b. A facilitation of dyslexia through a remediation of Shakespeare's text, Research in Drama Education: The Journal of Applied Theatre and Performance, 21:3, 385400 To link to this article: http://dx.doi.org/10.1080/13569783.2016.1194191

Yin, R., 2009. Case Study Research: Design and Methods. $4^{\text {th }}$ Ed. Sage Publications Inc, California.

Zybutz, T. and Farquharson, C., 2016. Psychophysical Performance and the Dyspraxic Actor. Journal of Neurodiversity in Higher Education Issue 2 76-87 Association of Dyslexic Specialists in Higher Education 